\title{
Remoção de microcistina-LR de águas eutrofizadas por clarificação e filtração seguidas de adsorção em carvão ativado granular
}

\author{
Removal of microcystin-LR from eutrophic waters through clarification \\ and filtration followed by adsorption on granular activated carbon
}

\begin{abstract}
Alaine de Brito Guerra', Marina Caldeira Tonucci², Beatriz Susana Ovruski de Ceballos ${ }^{3}$, Hindria Renally Cavalcanti Guimarães ${ }^{4}$, Wilton Silva Lopes ${ }^{5}$, Sérgio Francisco de Aquino ${ }^{6}$, Marcelo Libânio7
\end{abstract}

\begin{abstract}
RESUMO
Usualmente, o tratamento convencional de águas com altas densidades de cianobactérias e concentração de cianotoxinas não garante efluente consoante o padrão de potabilidade vigente $\left(1,0 \mu \mathrm{g} \cdot \mathrm{L}^{-1}\right.$ de microcistina). Etapas adicionais fazem-se necessárias, destacando-se a adsorção por carvão ativado granular ou pulverizado. Neste contexto, o objetivo geral deste trabalho foi avaliar em escala de bancada a remoção de microcistina em água natural por adsorção em colunas de carvão ativado granular de casca de coco, após as etapas de clarificação e filtração em areia. Os resultados mostraram que o transpasse no carvão de maior granulometria ocorreu em menor tempo de contato ( $2 \mathrm{~h}$ ), quando comparado ao de menor granulometria. Tais resultados abrem perspectiva de emprego em escala real por garantir efluente com concentração inferior ao que estabelece a Portaria 2914 por mais tempo e utilizando menor massa de carvão.
\end{abstract}

Palavras-chave: adsorção; cianotoxinas; microcistina-LR; carvão ativado granular; tratamento convencional.

\begin{abstract}
Conventional treatment process of natural waters with high densities of cyanobacteria and cyanotoxins usually presents low efficiency according to the present drinking water standard (maximum permissible value of $1.0 \mathrm{~g}$ g.L-1 of microcystin). Additional steps, such as activated carbon, commonly become necessary to achieve the maximum permissible value of microcystin $\left(1.0 \mu \mathrm{g} . \mathrm{L}^{-1}\right)$ set up by Brazilian Drinking Water Regulation 2914. In this context, the main objective of this work was to evaluate microcystin removal from natural waters by means of two granular activated carbons after clarification and sand filtration in bench scale. The results pointed out that the breakthrough happened in activated carbon with highest grain sizes in lower contact time $(2 \mathrm{~h})$, when compared with that with smaller grain sizes. These results open the perspective of an application of the activated carbon in actual scale, assuring the treated water quality in compliance with the Brazilian Drinking Water Standards Regulation 2914.
\end{abstract}

Keywords: adsorption; cyanotoxins; microcystin-LR, granular activated carbon; conventional water treatment.

\section{INTRODUÇÃO}

Florações de cianobactérias em corpos de águas naturais têm sido relatadas em todo o mundo. Na Paraíba, vários estudos mostram a ocorrência de cianobactérias potencialmente toxigênicas em pelo menos 18 dos 20 reservatórios de acumulação (denominados regionalmente açudes) com capacidade superior a 30 milhões de $\mathrm{m}^{3}$ e que representam cerca de $80 \%$ da capacidade de armazenamento das águas superficiais do Estado. Em 13 desses reservatórios, detectou-se microcistina-LR (MC-LR) em concentrações que variaram de $0,5 \mu \mathrm{g} . \mathrm{L}^{-1}$ (em dois reservatórios) a superiores a 1,0 $\mu \mathrm{g} \cdot \mathrm{L}^{-1}$ (em 11). O quarto maior reservatório do Estado, o açude Acauã, com 253 milhões de $\mathrm{m}^{3}$ - localizado na bacia hidrográfica do médio Rio Paraíba e que abastece em torno de 37.000 habitantes — apresenta registros de florações permanentes de cianobactérias desde sua inauguração em 2002. Concentrações entre

'Doutoranda em Biotecnologia pela Universidade Federal do Rio Grande do Norte (UFRN) - Natal (RN), Brasil. ${ }^{2}$ Mestre em Engenharia Ambiental pela Universidade Federal de Ouro Preto (UFOP) - Ouro Preto (MG), Brasil.

${ }^{3}$ Doutora em Microbiologia Ambiental pela Universidade de São Paulo (USP). Professora Titular do Departamento de Ciências Biológicas da Universidade Estadual da Paraíba (UEPB) - Campina Grande (PB), Brasil.

${ }^{4}$ Mestre em Ciência e Tecnologia Ambiental pela UEPB - Campina Grande (PB), Brasil.

5Doutor em Química pela Universidade Federal da Paraíba (UFPB). Professor do Departamento de Engenharia Sanitária e Ambiental da UEPB - Campina Grande (PB), Brasil.

${ }^{6}$ Doutor em Engenharia Química pela Universidade de Londres. ProfessorAssociado do Departamento de Química da UFOP - Ouro Preto (MG), Brasil.

${ }^{7}$ Professor Titular do Departamento de Engenharia Hidráulica e Recursos Hídricos da UFOP - Belo Horizonte (MG), Brasil.

Endereço para correspondência: Marcelo Libânio - Avenida Antônio Carlos, 6.627 - 31270-901 - Pampulha (BH), Brasil - Email: mlibanio@ehr.ufmg.br

Recebido: 18/12/12 - Aceito: 09/02/15 - Reg. ABES: 108649 
3,79 a 27,29 $\mu \mathrm{g} . \mathrm{L}^{-1}$ de MC-LR já foram detectadas neste corpo aquático (VASCONCELOS et al., 2011).

As microcistinas constituem as cianotoxinas isoladas com maior frequência e que têm provocado maior número de intoxicações humanas em todo o mundo, sendo produzidas por pelo menos seis gêneros de cianobactérias incluindo Microcystis, Plankthotrix (Oscillatoria), Anabaena e Nostoc. Essas toxinas são heptapeptídeos monocíclicos compostos por sete aminoácidos, incluindo um aminoácido incomum (ADDA - 3-amino-9-metoxi-2,6,8-trimetil-10-fenildeca-4,6-dienóico), determinado como um dos responsáveis pela atividade biológica dessas hepatotoxinas. Dentre as mais de 80 variantes moleculares de microcistinas isoladas, seis apresentam maior destaque (MC-LR, MC-LA, MC-YR, MC-RR, MC-LF e MC-LW), sendo a variante que contém a leucina e arginina (MC-LR) a mais abundante (SIVONEN \& JONES, 1999).

A Organização Mundial de Saúde (WHO, 1998) introduziu nos “Guias sobre qualidade de água de consumo humano" valores máximos permissíveis para microcistina, após a morte de 52 pacientes em uma clínica de hemodiálise em Caruaru (PE) que receberam água contaminada com hepatoxinas. No Brasil, a microcistina foi incluída como parâmetro de monitoramento na Portaria 1469 (BRASIL, 2000) e desde então tem sido utilizada no controle de qualidade de água para consumo humano. Atualmente, a Portaria 2914 (BRASIL, 2011) exige a análise de microcistinas na água para tal consumo, estabelecendo o valor máximo permissível de 1,0 $\mu \mathrm{g} \cdot \mathrm{L}^{-1}$.

Uma das rotas mais comuns de exposição humana às cianotoxinas é a ingestão de água contaminada. O procedimento convencional (clarificação/filtração/desinfecção) é a tecnologia de tratamento de água de uso predominante no Brasil. Segundo dados do IBGE (2008), há cerca de 2.817 municípios dotados de estações de tratamento convencional, dentre os quais 104 na Região Norte, 851 na Nordeste, 1.087 na Sudeste, 545 na Sul e 230 na Centro-oeste. Neste cenário, considerando que diversos municípios dispõem de mais de uma unidade de potabilização, estima-se que mais de 3500 estações convencionais estejam em operação no país. Embora predominem em quantidade, diversas dificuldades são observadas na remoção de cianobactérias e cianotoxinas.

A remoção de células intactas de cianobactérias deve ser priorizada, tendo em vista a redução significativa das concentrações de precursores de sabor, odor e substâncias tóxicas na água tratada. Para identificar eventual lise celular no tratamento convencional é necessário avaliar cuidadosamente cada etapa do processo. Aspecto importante desta avaliação é o efeito do coagulante sobre as células. Estudos realizados por Chow et al. (1999) demonstraram, em escala de bancada e piloto, que a adição de sulfato de alumínio ou cloreto férrico e a ação mecânica da mistura rápida e da floculação não provocam nenhum dano às células de Microcystis aeruginosa.

Em situações em que a toxina é eliminada ou liberada pela célula por algum processo de lise celular, envelhecimento (senescência) ou ação de fatores ambientais, o tratamento convencional não tem se manifestado eficiente na remoção das cinotoxinas dissolvidas. Quando tal dispersão na massa líquida ocorre, a adsorção por carvão ativado tem sido demonstrada por vários estudos como eficaz na remoção de cianotoxinas (DRIKAS; DIXON; MORRAN, 2009).

A adsorção de contaminantes por carvão ativado é um processo complexo, podendo ser classificado como físico ou químico. A adsorção física é reversível e ocorre quando forças de atração molecular entre o soluto e o adsorvente são maiores do que as forças de atração entre soluto e solvente. Assim, o soluto será adsorvido pela superfície do carvão através das forças de atração de van der Waals. Na adsorção química, a reação ocorre entre a superfície do carvão e o soluto adsorvido, sendo a reação geralmente irreversível (BRADY, 1990).

De acordo com Snoeying e Summers (1990), o pH, a área superficial, a distribuição de tamanho dos poros e as características químicas da superfície do carvão ativado são os principais fatores que afetam o processo de adsorção. O primeiro fator manifesta-se ao determinar a carga de superfície do carvão ativado e da molécula a ser adsorvida, governando assim as interações eletrostáticas entre o adsorvato e o adsorvente. $\mathrm{O} \mathrm{pH}_{\mathrm{pcz}}$ pode ser interpretado como o $\mathrm{pH}$ cujo balanço de cargas é nulo. Para valores de $\mathrm{pH}$ superiores ao do $\mathrm{pH}_{\mathrm{pcz},}$ a superfície do carvão se apresentará negativa, enquanto que abaixo deste valor será positiva. A importância desta variável na adsorção manifesta-se quando as cargas do adsorvato e do adsorvente são opostas para que haja maior interação entre ambos. Caso as cargas sejam iguais, o processo de adsorção será prejudicado, pois haverá repulsão eletrostática. Entretanto, cabe destacar que a interação eletrostática é importante para aproximar o adsorvente do adsorvato, mas não é condição obrigatória para a adsorção ocorrer. Há vários exemplos de adsorção de solutos que não desenvolvem carga no $\mathrm{pH}$ de trabalho (BAUTISTA-TOLEDO et al., 2005).

A área superficial específica do carvão constitui um dos parâmetros mais importantes na determinação de sua capacidade adsortiva. Geralmente, quanto maior seu valor, maior a capacidade de adsorção. Carvões ativados utilizados como adsorventes apresentam área superficial da ordem de 800 a $1500 \mathrm{~m}^{2} \cdot \mathrm{g}^{-1}$. Outra característica fundamental na adsorção é a distribuição dos tamanhos dos poros. Carvões com diâmetros inferiores a 8 Å são classificados como microporosos primários, entre 8 e $20 \AA$ Å como microporosos secundários, enquanto que de 20 a $500 \AA$ como mesoporosos e, acima de $500 \AA$, macroporosos (NEWCOMBE, 2006). Carvões utilizados como adsorventes normalmente apresentam volume de poros de $0,20 \mathrm{a} 0,60 \mathrm{~cm}^{3} \cdot \mathrm{g}^{-1}$ (BRADY, 1990).

Para Huang, Cheng e Cheng (2007), na adsorção da MC-LR é necessário considerar que se trata de uma molécula grande $\left(995,17\right.$ g.mol $\left.{ }^{-1}\right)$ constituída por agregado complexo de aminoácido com caráter hidrofóbico. Desse modo, a seleção adequada do carvão ativado para remoção de MC-LR de solução aquosa requer a apreciação dessas propriedades combinadas, assim como o conhecimento detalhado das propriedades físico-químicas de superfície do adsorvente. 
A maioria dos estudos relacionados à adsorção de MC-LR sugere carvões à base de madeira como mais adequados à adsorção devido ao grande volume de mesoporos. A conformação das moléculas, juntamente às características de volume de poros do carvão, especialmente o predomínio de microporos secundários e mesoporos, são características de fundamental importância na adsorção das microcistinas (PENDLETON; SCHUMANN; WONG, 2001; KURODA et al., 2005; SATHISHKUMAR et al., 2010). Como as moléculas de MC-LR e MC-RR apresentam comprimento na faixa de 1,4 a 2,94 nm, há maior possibilidade de ambas serem facilmente adsorvidas pelos microporos secundários $(0,8-2,0 \mathrm{~nm})$ e mesoporos (2-50 nm) (SATHISHKUMAR et al., 2011).

Diante do exposto, esse trabalho avalia em escala de bancada a remoção de MC-LR em águas eutrofizadas por adsorção em carvão ativado granular, após as etapas de clarificação e filtração em areia e a influência de duas distintas granulometrias do carvão ativado granular de casca de coco na remoção de MC-LR.

\section{METODOLOGIA}

\section{Cultivo de Microcystis aeruginosa e obtenção de microcistina-LR}

A cepa de Microcystis aeruginosa, isolada a partir de amostras coletadas no Reservatório do Rio Tietê (Barra Bonita/São Paulo) e cedida pelo Departamento de Botânica da Universidade Federal de São Carlos/SP, foi cultivada pelo método Batch (repique) em meio de cultura AS-M1, sob aeração, temperatura de $25^{\circ} \mathrm{C}$, fotoperíodo de 12 horas e intensidade luminosa em torno $96 \mu \mathrm{mol} . \mathrm{cm}^{-2} \cdot \mathrm{s}^{-1}$. Após alcançar $10^{7}$ células. $\mathrm{mL}^{-1}$, a cultura foi congelada e descongelada (três vezes), para promover a lise celular e liberar a toxina intracelular para o meio, e posteriormente filtrada em membranas com poros de 1,0 $\mu \mathrm{m}$ (Whatmam GFC/Fibra de vidro) e de $0,45 \mu \mathrm{m}$ (Millipore). O filtrado, denominado de extrato bruto de MC-LR, foi homogeneizado e congelado para a posterior utilização.

\section{Caracterização do carvão ativado}

Foram avaliadas duas granulometrias de carvão ativado granular (CAG), produzido a partir da casca de coco de dendê e comercialmente disponível (Carbonmar, Brasil): 12 x 40 mesh (CAG1) e 8 x 30 mesh (CAG2). Os carvões foram caracterizados quanto à densidade $\left(\mathrm{g} . \mathrm{cm}^{-3}\right)$, superfície específica BET $\left(\mathrm{m}^{2} \cdot \mathrm{g}^{-1}\right)$, volume $\left(\mathrm{cm}^{3} \cdot \mathrm{g}^{-1}\right)$, área e tamanho médio de microporos, volume total $\left(\mathrm{cm}^{3} \cdot \mathrm{g}^{-1}\right)$, diâmetro máximo e diâmetro médio de poros utilizando o princípio de adsorção do gás nitrogênio na superfície do sólido por meio dos métodos BET e BJH. O pHpcz foi determinado de acordo com o proposto por Valdés et al. (2002). Maiores informações acerca das técnicas utilizadas podem ser observadas no trabalho de Teixeira et al. (2012). Na Tabela 1 são apresentadas informações das colunas de CAG utilizadas.

\section{Preparação e caracterização da água de estudo}

A água de estudo, oriunda do açude Acauã, foi coletada na entrada da estação de tratamento de Itatuba/PB, adicionando-se 22,30 mL.L ${ }^{-1}$ de extrato bruto de MC-LR. O volume do extrato adicionado correspondeu à concentração de aproximadamente $20 \mu \mathrm{g} \cdot \mathrm{L}^{-1}$ de MC-LR, uma vez que a análise prévia desse extrato evidenciou concentração de $881 \mu \mathrm{g} \cdot \mathrm{L}^{-1}$. Apesar da água coletada apresentar predomínio de espécies de cianobactérias potencialmente produtoras de cianotoxinas como Planktothrix agardhii, Pseudoanabaena limnetica, Cylindrospermopsis raciborskii e Aphanizomenom sp, durante a realização do experimento não foi detectada MC-LR sendo, portanto, necessária sua adição.

A água de estudo foi caracterizada quanto ao $\mathrm{pH}$, turbidez e cor aparente, utilizando métodos padrões (APHA; AWWA; WEF, 2005) e quantificada a concentração de microcistina-LR (no extrato bruto assim como das amostras provenientes do ensaio em bancada) pelo ensaio ELISA (Enzyme-Linked ImmunoSorbent Assay), utilizando o Kit Beacon Microcistina Placa (marca Beacon Analytical Systems Inc., Estados Unidos). A faixa de detecção do ensaio é de $0,1-2,0 \mu \mathrm{g} \cdot \mathrm{L}^{-1}$.

\section{Descrição do aparato experimental}

Utilizou-se equipamento Jar test para simular as etapas de coagulação, floculação e sedimentação (de acordo com parâmetros previamente definidos). A água decantada era armazenada em tanque de $20 \mathrm{~L}$ acoplado a bomba dosadora para recalque aos filtros de areia e do efluente destes às colunas de carvão ativado granular. Os filtros de areia e as colunas de CAG foram montados em tubos de PVC com diâmetro interno de $21 \mathrm{~mm}$ e altura útil de areia e de carvão fixada em $15 \mathrm{~cm}$. Na Figura 1, apresenta-se o desenho esquemático do aparato experimental.

Por se tratar de um sistema contínuo, para o qual a demanda de água decantada deveria se manter constante, definiu-se para cada filtro de areia e para a coluna de carvão ativado vazão afluente de 2,0 L.h ${ }^{-1}$. O sistema operou durante $72 \mathrm{~h}$ e a coleta da água decantada, dos afluentes e efluentes dos filtros de areia e das colunas de carvão ativado granular realizou-se a cada $2 \mathrm{~h}$.

Tabela 1 - Informações das colunas de carvão ativado granular utilizadas no aparato experimental.

\begin{tabular}{l|c|c}
\multirow{2}{*}{ Características } & \multicolumn{2}{|c}{ Coluna de carvão ativado granular } \\
\cline { 2 - 3 } Granulometria (mm) & CAG1 & CAG2 \\
\hline Massa (g) & 0,42-1,40 & 0,60-2,36 \\
\hline Tempo de contato teórico (s) & 30,63 & 31,79 \\
\hline Altura (cm) & 45 & 45 \\
\hline Volume da coluna (mL) & 15 & 15 \\
\hline Volume de vazio na coluna $(\mathrm{mL})$ & 52 & 52 \\
\hline
\end{tabular}


Os ensaios de coagulação foram realizados em equipamento de Jar test, marca MILAN, apto a conferir gradientes de velocidade máximos de $120 \mathrm{~s}^{-1}$. Os parâmetros hidráulicos inerentes às etapas de mistura rápida, floculação e decantação utilizados nos ensaios de Jar test foram:

- mistura rápida: tempo de agitação de 60 s e gradiente de velocidade

(G) de $120 \mathrm{~s}^{-1}$, culminando com produto Gt da ordem de 7.200;

- floculação: tempo de floculação de 20 min e gradiente de velocidade constante de $40 \mathrm{~s}^{-1}$;

- velocidade de sedimentação de $1,4 \mathrm{~cm} \cdot \mathrm{min}^{-1}$, equivalente à taxa de aplicação superficial de $20,2 \mathrm{~m}^{3} \cdot \mathrm{m}^{-2} \cdot \mathrm{dia}^{-1}$.

Os parâmetros dos ensaios relativos à clarificação, à exceção daqueles referentes à coagulação, fiaram-se nas recomendações da NBR 12216 (ABNT, 1992). Vale mencionar que a velocidade de sedimentação se vincula ao objetivo principal da unidade de decantação. Desta forma, para o presente estudo adotou-se velocidade mínima recomendada para águas com elevada concentração algal.

Em relação aos parâmetros de mistura rápida cabe salientar que, na maioria das estações de tratamento brasileiras, a mesma ocorre em medidores Parshall, nos quais gradientes de velocidade da ordem de $1.400 \mathrm{~s}^{-1}$ associam-se a tempos de detenção inferiores a $0,5 \mathrm{~s}$, culminando no produto Gt da ordem de 700. Como o objetivo principal do trabalho foi avaliar a remoção de MC-LR por adsorção em carvão ativado granular, privilegiou-se a mais fácil exequibilidade dos ensaios, daí a opção por tempo de agitação somente passível de ocorrer em tanques de mistura rápida dotados de agitadores tipo turbina, comuns em estações nos EUA e Canadá. Em semelhante contexto, não se realizaram ensaios de tratabilidade visando à definição das condições ótimas de clarificação, já que a adsorção em carvão ativado se constituía no cerne da pesquisa.

Por fim, ensaios prévios com cinco coagulantes primários realizados com a água de estudo evidenciaram a supremacia do cloreto de polialumínio líquido $-\mathrm{Al}_{\mathrm{n}}(\mathrm{OH})_{\mathrm{m}} \mathrm{Cl}_{3 \mathrm{~nm}}\left(18 \%\right.$ de $\left.\mathrm{Al}_{2} \mathrm{O}_{3}\right)$ - na dosagem de 9,92 mg.L $\mathrm{L}^{-1}$ de $\mathrm{Al}^{3+}$ e pH de coagulação de 6,6. Nestas condições, obtiveram-se os melhores resultados em termos de remoção de turbidez, cor aparente e verdadeira, e algas e cianobactérias, justificando sua escolha para a realização do trabalho.

\section{RESULTADOS E DISCUSSÃO}

\section{Remoção de microcistina-LR}

Os valores médios dos principais parâmetros de qualidade da água no sistema em bancada estão apresentados nas Figuras 2 e 3.

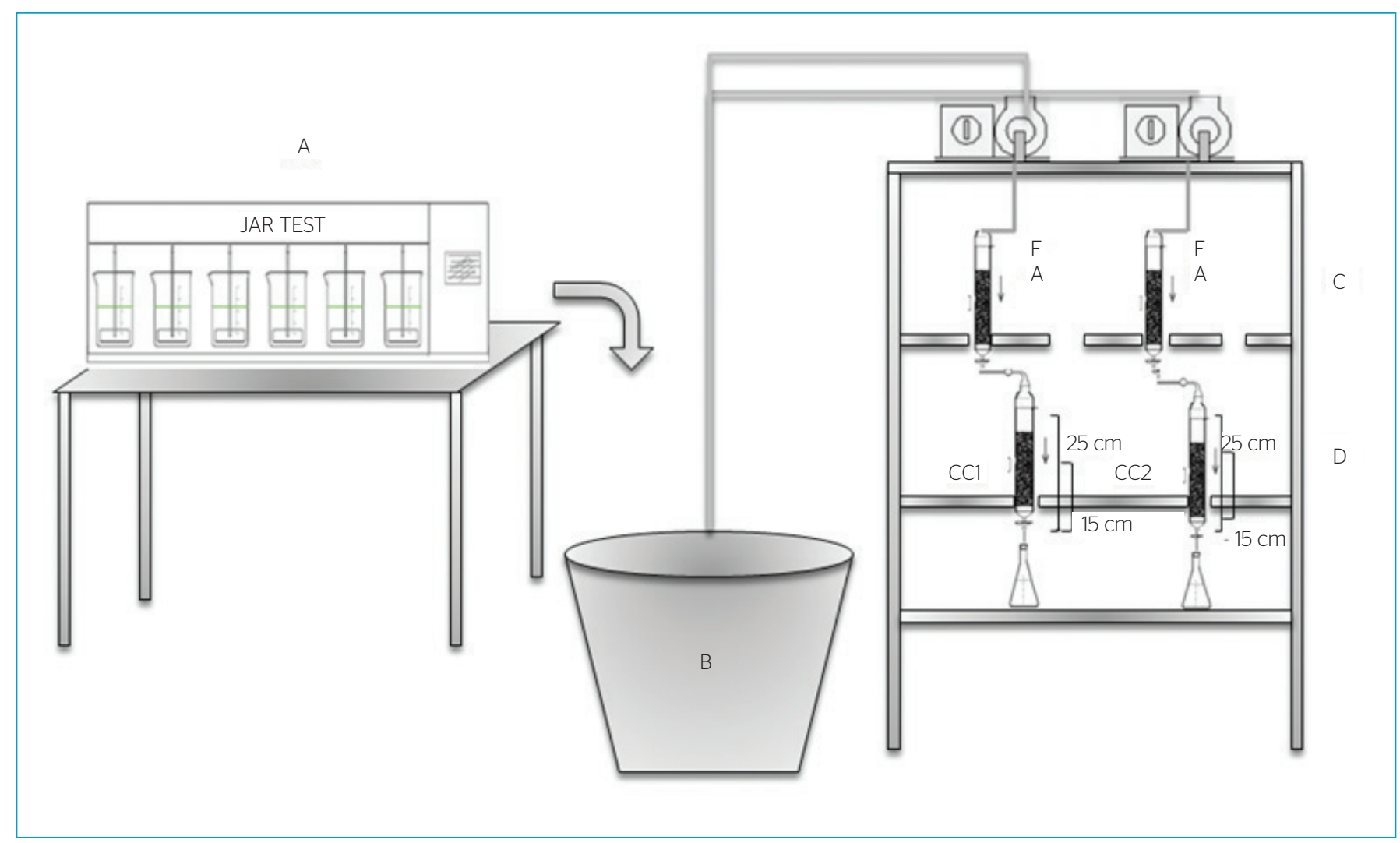

Figura 1 - Aparato experimental representando as etapas de clarificação (A), armazenamento da água decantada (B), filtração em areia (C) e colunas de carvão ativado granular (D). 
Conforme previsto, as etapas que compõem o tratamento convencional se mostraram eficientes na remoção de turbidez e cor aparente (Figura 2) e pouco eficientes na remoção de MC-LR (Figura 3). Verificaram-se remoções médias de 13 a 14\% após a sedimentação, e de apenas 6 a 7\% após a filtração em areia, afluindo às colunas de CAG, efluente com concentração média de MC-LR 18 vezes superior ao permitido pela Portaria $2914\left(1,0 \mu \mathrm{g} . \mathrm{L}^{-1}\right)$. Tal constatação confirmou mais uma vez a limitação do tratamento convencional na remoção de compostos dissolvidos e a necessidade de etapa complementar para adequação ao padrão de potabilidade.
Ao contrário do tratamento convencional sem a adição de cloro, o uso do carvão ativado promoveu a remoção média de 75 a 85\% de MC-LR durante as $72 \mathrm{~h}$ de monitoramento. A diminuição da capacidade de remoção com o tempo foi atribuída à matéria orgânica natural (MON) da água e da toxina não purificada adicionada à água de estudo, que certamente competiu pelos sítios de adsorção na superfície do CAG. Além disso, a MON pode também ter reduzido a capacidade de adsorção de microcistina por mecanismos de bloqueio de poros (WANG et al., 2007). Remoções maiores, porém considerando menor concentração de microcistina purificada (sem a presença de matéria orgânica), foram observadas pelos mesmos autores ao avaliarem a

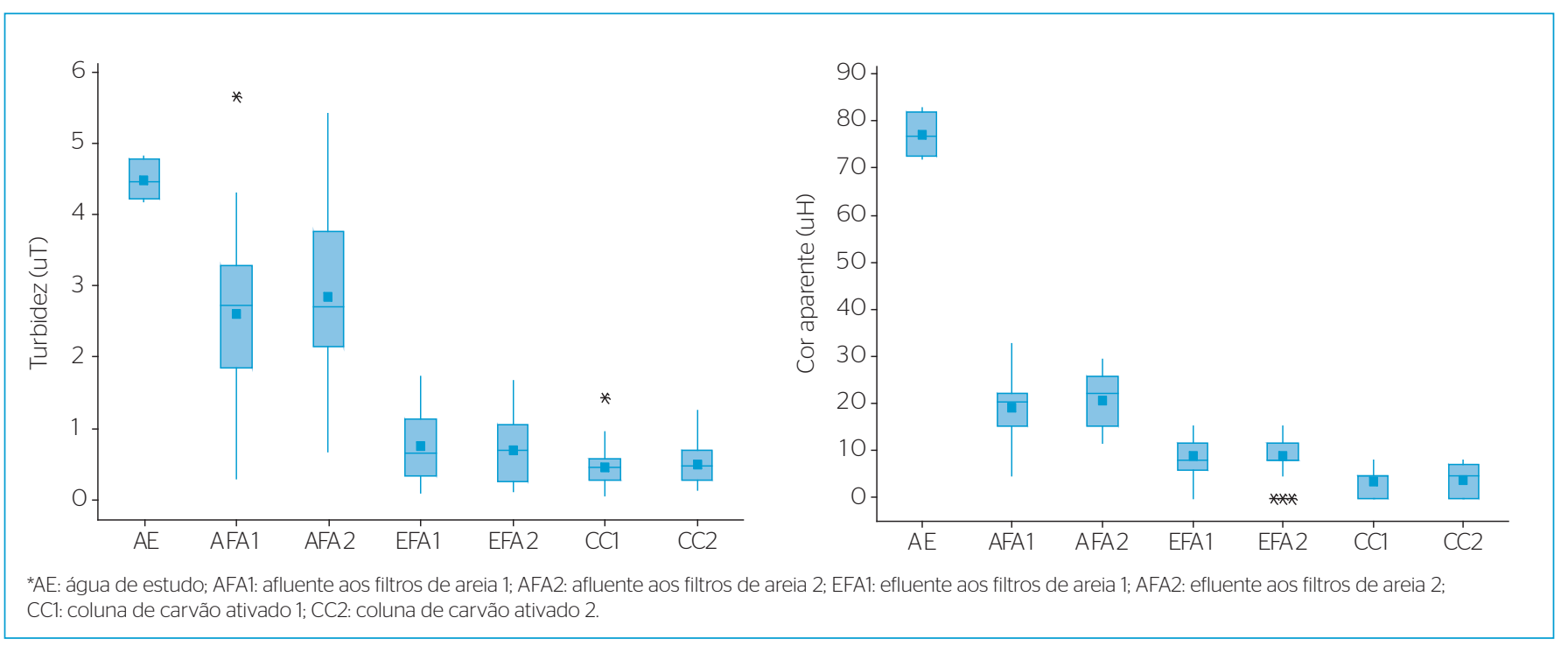

Figura 2 - Valores médios da turbidez e cor aparente na água de estudo, na água decantada afluente aos filtros de areia, e nos efluentes dos filtros de areia e das colunas de carvão ativado.

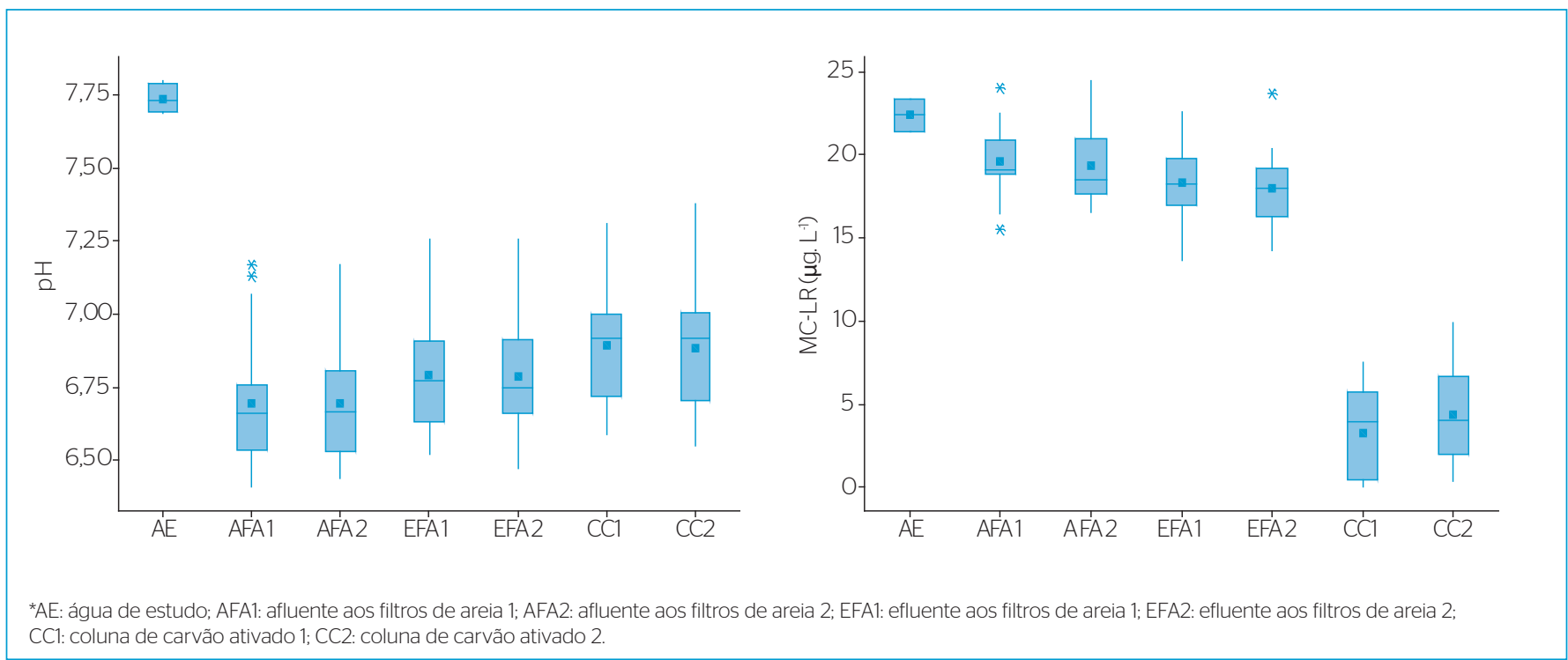

Figura 3 - Valores médios da pH e de concentração de microcistinaLR na água de estudo, na água decantada afluente aos filtros de areia e nos efluentes dos filtros de areia e das colunas de carvão ativado. 
adsorção na água tratada acrescida de $5 \mu \mathrm{g} . \mathrm{L}^{-1}$ de MC-LR. Utilizando coluna com GAC estéril, observouse diminuição gradativa da capacidade de adsorção após remoção completa inicial nos primeiros dias e de aproximadamente 70\% após seis meses de operação.

A concentração de MC-LR no efluente das colunas com carvões de distintas granulometrias apresenta-se na Figura 4. O efluente do CAG1 após $10 \mathrm{~h}$ de funcionamento manifestou concentração de MC-LR próxima ao dobro $\left(1,9 \mu \mathrm{g} . \mathrm{L}^{-1}\right)$ do mencionado limite estabelecido pela Portaria 2914, enquanto na coluna com CAG2 concentrações acima do limite estabelecido pela mesma foram observadas após $2 \mathrm{~h}$ de funcionamento (concentrações de 1,9 $\mu \mathrm{g} \cdot \mathrm{L}^{-1}$ após $4 \mathrm{~h}$ e 1,2 $\mu \mathrm{g} \cdot \mathrm{L}^{-1}$ após $6 \mathrm{~h}$ de funcionamento).

\section{Curva de trespasse e cinética de Thomas}

O volume de trespasse (breakthrough volume), definido como o volume para o qual a concentração de MC-LR no efluente atinge 1,0 $\mu$ g. $\mathrm{L}^{-1}$, foi 2,7 vezes mais elevado para o CAG1 (16 L) do que para o CAG2 (6 L), considerando que a massa de carvão utilizada foi praticamente igual. $\mathrm{Na}$ Figura 4, são apresentados gráficos relacionando a concentração final e inicial de MC-LR, em função do volume de leito para as duas colunas de carvão.

Os dados fornecidos pelo ensaio em coluna e os resultados da curva de trespasse prestaramse a avaliar o ajuste experimental ao modelo cinético de Thomas (JUANG; KAO; CHEN, 2006), que permite a determinação da constante de Thomas $\left(\mathrm{K}_{\mathrm{TH}}\right)$ e da capacidade máxima de adsorção $\left(Q_{\max }\right)$ do carvão.

A forma linear do modelo de Thomas (MALKOC \& GÖNEN, 2006) é expressa pela Equação 1: $\ln \left(\frac{C_{0}}{C}-1\right)=\frac{K_{T H} Q_{\max } M}{Q}-\frac{K_{T H} Q_{o} V}{Q}$

$\mathrm{Na}$ qual:

$C_{\mathrm{o}}$ : concentração de MC-LR afluente à coluna $\left(\mathrm{mg} \cdot \mathrm{L}^{-1}\right)$;

C: concentração de MC-LR efluente da coluna (mg. $\left.\mathrm{L}^{-1}\right)$;

$K_{\mathrm{TH}}$ : constante de Thomas $\left(\mathrm{mL} \cdot \mathrm{min}^{-1} \cdot \mathrm{mg}^{-1}\right)$ cujo inverso reflete a constante de equilíbrio do fenômeno de adsorção $\left(1 / \mathrm{K}_{\mathrm{TH}}=\mathrm{k}_{\mathrm{eq}}\right.$ usualmente expressa em mol. $\left.\mathrm{L}^{-1} \cdot \mathrm{min}^{-1}\right)$;

$\mathrm{Q}_{\max }$ : capacidade máxima de soluto adsorvido pelo sólido adsorvente (mg.g $\mathrm{g}^{-1}$ );

$V$ : volume efluente $(\mathrm{mL})$;

M: massa de adsorvente (g);

Q: vazão $\left(\mathrm{mL} \cdot \mathrm{min}^{-1}\right)$.

Na Figura 5, apresenta-se a função linear logarítmica do modelo de Thomas que permitiu a determinação da constante $K_{\mathrm{TH}}$ e da capacidade de adsorção máxima do adsorvente $\left(\mathrm{Q}_{\max }\right)$, tal como apresentado na Tabela 2 .

Conforme observa-se na Tabela 2, a quantidade máxima de MC-LR adsorvida por unidade de carvão $\left(\mathrm{Q}_{\max }\right)$ foi bem maior para a coluna de carvão ativado de menor granulometria (CAG1), sugerindo seu uso em escala real. Huang, Cheng e Cheng (2007) obtiveram, por meio de isotermas de adsorção aplicadas ao modelo de Langmuir, valores de $Q_{\max }$ de 16,1 mg.g ${ }^{-1}$ para o carvão de casca de coco, 17,5 mg.g ${ }^{-1}$ para o carvão betuminoso, $14,5 \mathrm{mg} \cdot \mathrm{g}^{-1}$ para um carvão não poroso e valores próximos aos obtidos para o CAG1 com carvão de madeira $\left(Q_{\max }\right.$ de 83,3 mg. $\left.\mathrm{g}^{-1}\right)$. Segundo os autores, a semelhança nos valores de $\mathrm{Q}_{\max }$ do CAG de casca de coco e do betuminoso com o CAG não poroso
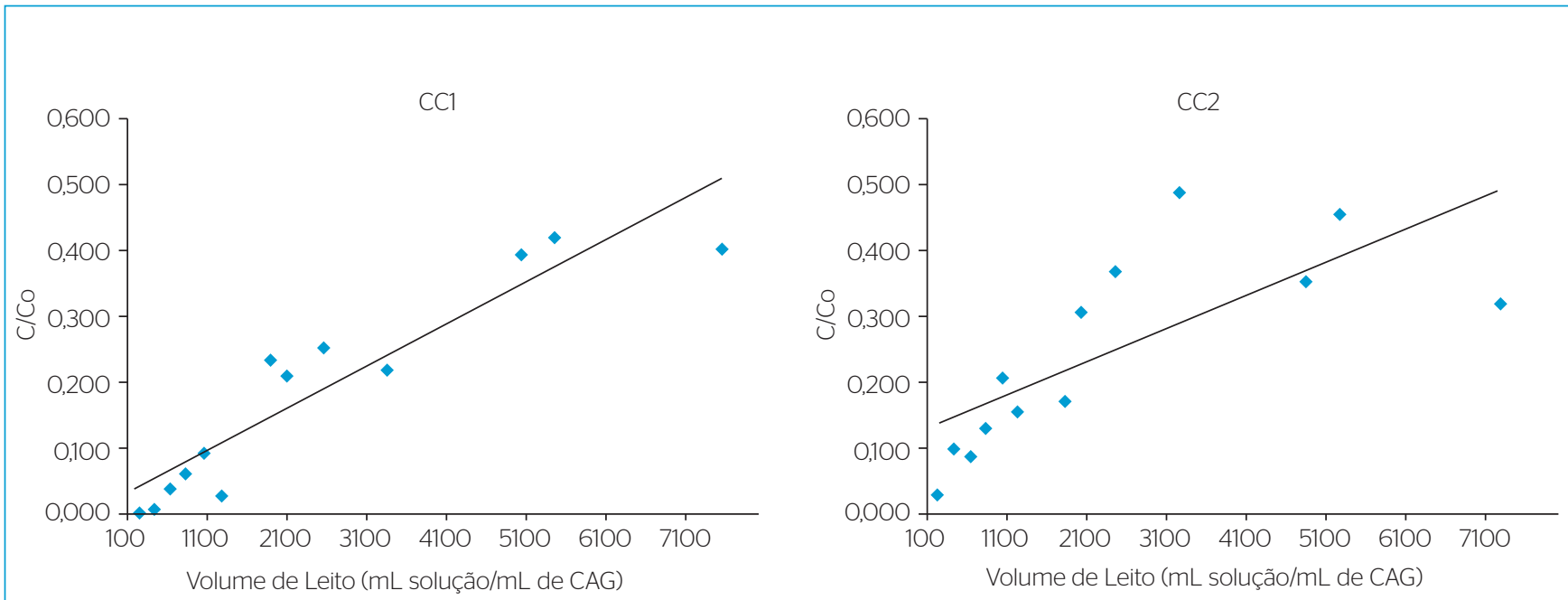

CCl: coluna de carvão ativado 1; CC2: coluna de carvão ativado 2; Co: concentração de MC-LR afluente à coluna (mg.Lำ); C: concentração de MC-LR efluente da coluna (mg.L'1); CAG: carvão ativado granular

Figura 4 - Relação entre a concentração final e inicial de microcistina-LR em função do volume de leito para as colunas com carvão ativado granular 1 (coluna de carvão ativado 1) e com carvão ativado granular 2 (coluna de carvão ativado 2). 
é indicativo que esses carvões apresentam superfície interna que não estava relacionada ao aumento na capacidade adsortiva.

A estimativa da taxa de uso do carvão nas colunas de CAG foi determinada segundo o método proposto por Di Bernardo e Dantas (2005) tal como apresentado na Equação 2:

$T . U=\frac{K_{0}-C}{Q_{e}}$

Na qual:

T.U: taxa de uso (gCAG.L $\left.{ }^{-1}\right)$;

Co: concentração de MC-LR afluente à coluna (mg.L $\left.\mathrm{L}^{-1}\right)$;

C: concentração de MC-LR de acordo com o máximo estabelecido pela Portaria 2914 (0,001 mg. $\left.\mathrm{L}^{-1}\right)$;

Qe: $\mathrm{Q}_{\text {máx }}$ determinado na cinética de Thomas $\left(\mathrm{mg} \cdot \mathrm{L}^{-1}\right)$.

Ao aplicar a Equação 2 para a CAG1, considerando que $\mathrm{Co}=18,0 \mu \mathrm{g} . \mathrm{L}^{-1}$ e $\mathrm{C}=1,0 \mu \mathrm{g} . \mathrm{L}^{-1}$, a taxa de uso será de 2,72 g CAG por litro água ou $0,36 \mathrm{~L}$ de água por grama de CAG. Considerando que $16 \mathrm{~L}$ de água passaram pela coluna até o transpasse do CAG1 e a massa de carvão usada (30,63 g), infere-se o valor de 0,52 L água por grama de CAG ou 1,92 g de CAG por litro de água. Ou seja, o valor experimental foi cinco vezes menor do que o calculado com base no $\mathrm{Q}_{\max }$ derivado do modelo de Thomas. Tal se deveu provavelmente à competição dos sítios adsortivos por outros compostos presentes no afluente à coluna de carvão e pelo próprio extrato da microcistina.

Para a CAG2 consideraram-se os mesmos valores de Co e C usados para CAG1, culminando com taxa de uso de 4,77 g CAG por litro de água ou 0,21 L água por grama de CAG. Como aproximadamente $6 \mathrm{~L}$ da água atravessaram a coluna até a ocorrência do transpasse, com a massa de carvão usada ( $31,79 \mathrm{~g})$ obtém-se $0,18 \mathrm{~L}$ água por grama de CAG ou 5,29 g CAG por litro de água.

\section{Caracterização do carvão}

Os carvões avaliados apresentaram valores de superfície específica muito próximos entre si (Tabela 3) e não foram compatíveis com as informações fornecidas pelo fabricante $\left(850 \mathrm{a} 1.000 \mathrm{~m}^{2} \cdot \mathrm{g}^{-1}\right)$. VeroneziViana et al., (2009) já alertavam sobre a importância da caracterização do carvão, uma vez que as informações fornecidas pelos fabricantes diferiram significativamente às características determinadas. Os elevados

Tabela 2 - Valores de $K_{\mathrm{TH}}$ (mL.min'. $\left.\mathrm{g}^{1}\right)$ e $Q_{\max }$ (mg.g') pelo modelo de Thomas para os carvões estudados.

\begin{tabular}{l|c|c|c}
\multicolumn{3}{|c|}{ Parâmetros do modelo de Thomas } \\
\hline Carvões & $\mathrm{K}_{\mathrm{TH}}\left(\mathrm{mL} \cdot \mathrm{min}^{1} \cdot \mathrm{g}^{1}\right)$ & $\mathrm{Q}_{\max }\left(\mathrm{mg} \cdot \mathrm{g}^{1}\right)$ & $\mathrm{R}^{2}$ \\
\hline CAG1 & 45,88 & 62,3 & 0,92 \\
\hline CAG2 & 80,29 & 35,6 & 0,98 \\
\hline
\end{tabular}

CAG1: carvão ativado granular 1; CAG2: carvão ativado granular 2

Tabela 3 - Caracterização dos carvões ativados granulares de distintas granulometrias.

\begin{tabular}{l|c|c} 
Características & CAG1 & CAG2 \\
\hline $\mathrm{pH}_{\mathrm{pcz}}$ & 9,58 & 9,11 \\
\hline Densidade $\left(\mathrm{g} \cdot \mathrm{cm}^{-3}\right)$ & 1,607 & 1,674 \\
\hline Superfície específica BET $\left(\mathrm{m}^{2} \cdot \mathrm{g}^{-1}\right)$ & 374,036 & 402,641 \\
\hline Volume de microporos $\left(\mathrm{cm}^{3} \cdot \mathrm{g}^{-1}\right)$ & 0,20900 & 0,21000 \\
\hline Tamanho médio dos microporos $(\AA)$ & 14,202 & 8,565 \\
\hline Volume total de poros $\left(\mathrm{cm}^{3} \cdot \mathrm{g}^{-1}\right)$ & 0,22510 & 0,22860 \\
\hline Diâmetro máximo dos poros $(\AA)$ & 754,00 & 637,00 \\
\hline Diâmetro médio dos poros $(\AA)$ & 18,22 & 12,03
\end{tabular}

CAG1: carvão ativado granular 1; CAG2: carvão ativado granular 2

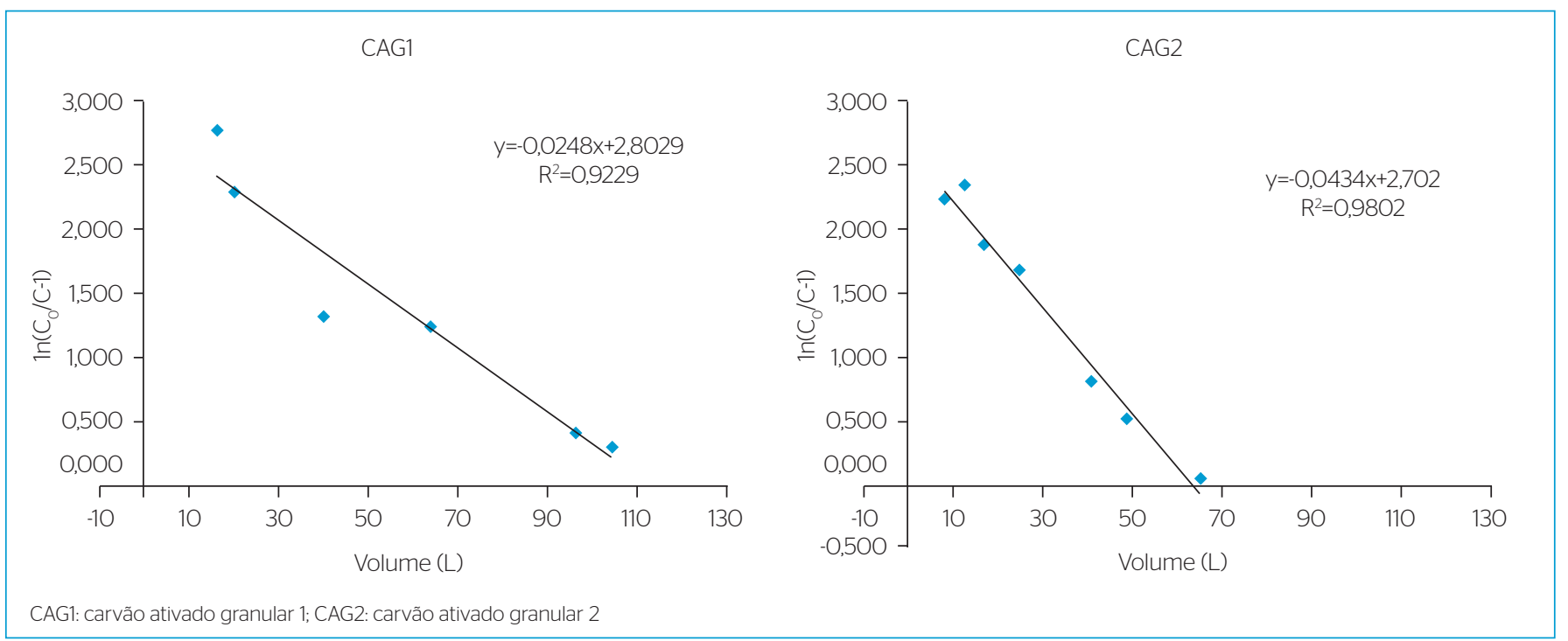

Figura 5 - Curva In $\left[\left(C_{0} / C\right)\right.$ 1] versus $V(L)$ do modelo Thomas para adsorção de microcistina-LR para os carvões estudados. 
valores de $\mathrm{pH}_{\mathrm{pcz}}$ obtidos para os carvões granulares indicam que os mesmos são básicos, e que tais materiais terão carga positiva no $\mathrm{pH}$ do afluente (média de 6,69), o que pode ter favorecido a adsorção de MC-LR por interações eletrostáticas, já que em valores de $\mathrm{pH}$ próximos à neutralidade, a molécula de MC-LR apresenta-se carregada negativamente (HO et al., 2011).

Ainda da análise da Tabela 3, apesar do diâmetro médio dos poros dos carvões avaliados serem diferentes entre si, depreende-se que ambos apresentaram valor entre 8 e $20 \AA$, classificandoos como dois carvões como microporosos secundários. Os dados de indicam que o volume de microporos representa cerca de 92 a $93 \%$ do volume total de poros. Como o comprimento máximo da MC-LR em qualquer ângulo é de $29 \AA$ e o menor é de $14 \AA$ (PENDLETON; SCHUMANN; WONG, 2001; SATHISHKUMAR et al., 2011), é possível que a MC-LR apresente maiores dificuldades em penetrar no microporo do CC2, cujo tamanho médio é de apenas $8 \AA$. Tal constatação pode explicar a menor capacidade de adsorção e menor volume de leito obtido para o CC2.

Os grupos funcionais presentes no carvão ativado granular, detectados pela Espectroscopia no Infravermelho por Transformada de Fourier (FTIR), são apresentados na Figura 6 e discutidos na Tabela 4.

Percebe-se, na superfície de ambos os carvões granulares, a presença de grupos nitrogenados (aminas, amidas) que conferem caráter básico ao material adsorvente, corroborando assim com os valores de $\mathrm{pH}_{\mathrm{pcz}}$. Tais grupamentos nitrogenados podem ser protonados em valores de $\mathrm{pH}$ próximos a 7,0 conferindo ao adsorvente excesso de cargas positivas, que parecem ter sido decisivas na adsorção de MC-LR.

\section{CONCLUSÕES}

A partir da revisão da literatura e dos resultados experimentais é possível concluir que:

- as etapas do tratamento convencional confirmaram-se pouco eficientes na remoção de microcistina-LR sendo, portanto, de fundamental importância a utilização do carvão ativado para atender os limites estabelecidos pela Portaria 2914;

- o carvão ativado granular de casca de coco manteve elevados percentuais de remoção da MC-LR apesar de predominantemente microporoso, mostrando-se eficiente mesmo diante de concentrações de toxina que representam caso extremo de contaminação;

- o transpasse no carvão de maior granulometria (CAG 2) ocorreu em menor tempo de contato $(2 \mathrm{~h})$, resultando em menor volume

Tabela 4 - Grupos funcionais do carvão detectados por espectroscopia FTIR. Bandas de vibração $\left(\mathrm{cm}^{-1}\right)$

\begin{tabular}{|c|c|}
\hline 3546 & Estiramento vibracional fenol $(\mathrm{O}-\mathrm{H})$ \\
\hline 3474 & \multirow{2}{*}{$\begin{array}{c}\text { Estiramento vibracional fraco } 35003400 \\
\text { em nheterocíclico Ex: Piridina - Pirrol } \\
\text { ou Estiramento de amida - } \mathrm{CONH}_{2} \\
\text { primária livre }\end{array}$} \\
\hline 3412 & \\
\hline 3238 & Estiramento vibracional de grupo $\equiv \mathrm{C}-\mathrm{H}$ \\
\hline 2024 & Estiramento de alcinos terminais $\mathrm{C} \equiv \mathrm{C}-\mathrm{H}$ \\
\hline 1633 & \multirow{2}{*}{ Vibração de $\mathrm{CH}_{2}$ no plano em R- $\mathrm{NH}_{2}$} \\
\hline 1612 & \\
\hline 1098 & Estiramento vibracional em grupo $\mathrm{C}-\mathrm{OH}$ \\
\hline 615 & Estiramento fora do plano em $\mathrm{N}-\mathrm{CH}_{2}$ \\
\hline
\end{tabular}

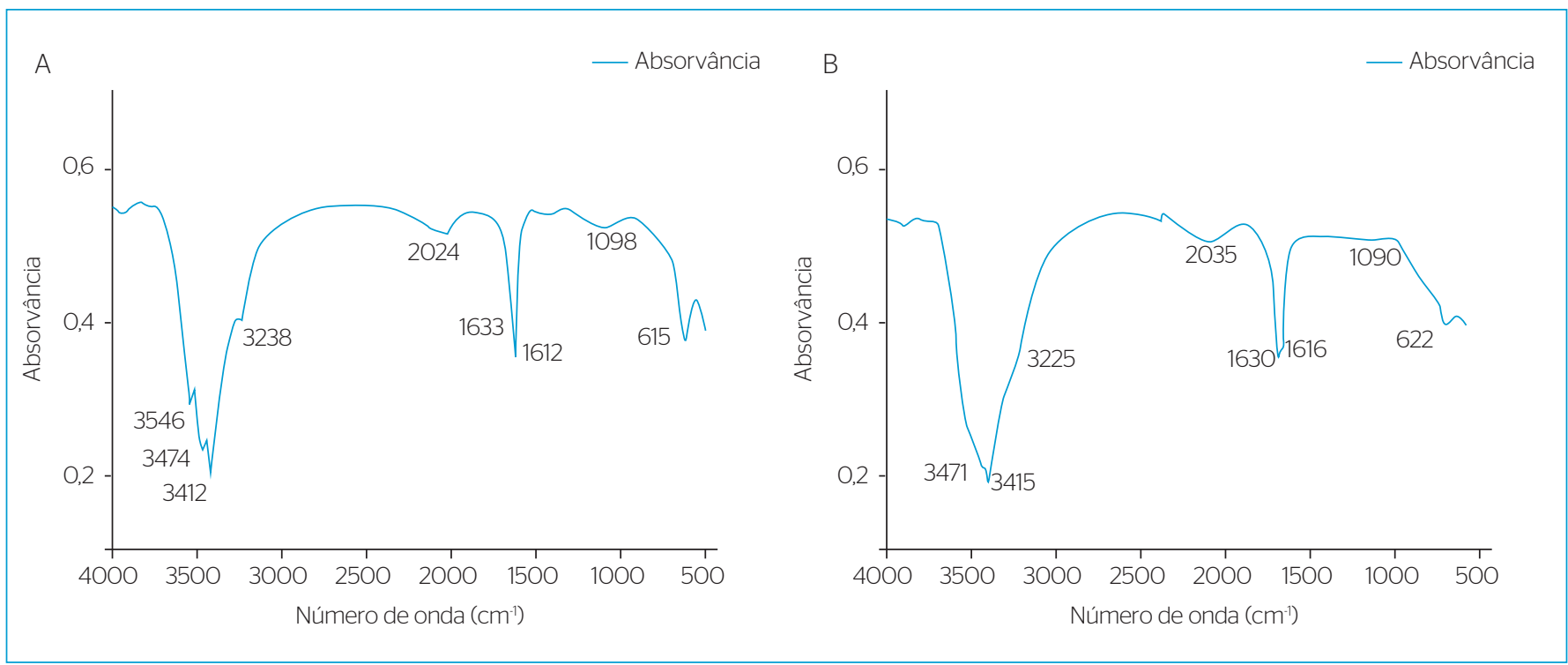

Figura 6 - Espectro FTIR do carvão ativado granular de casca de coco com diferentes granulometrias - (A) carvão ativado granular 1 (0,42-1,40 mm) e (B) carvão ativado granular $2(0,60-2,36 \mathrm{~mm})$. 
de transpasse $(6 \mathrm{~L})$ e menor massa adsorvida por unidade de massa de carvão $\left(Q_{\max }=35,5 \mathrm{mg} \cdot \mathrm{g}^{-1}\right)$, quando comparado ao de menor granulometria (CAG1);

- o CAG 1, por sua vez, apresentou melhor desempenho tanto em relação ao volume de transpasse $(16 \mathrm{~L})$ como pelo $Q_{\max }\left(62,3,3 \mathrm{mg} \cdot \mathrm{g}^{-1}\right)$, confirmando sua adequabilidade em escala real, uma vez que garantiu efluente com concentração inferior ao estabelecido pela Portaria 2914 por mais tempo e despendendo menor massa de carvão;

- o pH de coagulação próximo à neutralidade obtido na clarificação, além de maximizar a desinfecção com compostos de cloro, pode ter favorecido o processo de adsorção por assegurar ao carvão carga oposta à da MC-LR;
- embora a superfície específica seja um dos parâmetros mais importantes na determinação de capacidade adsortiva do carvão, a presença dos microporos secundários com tamanho compatível ao da molécula a ser adsorvida parece ter atuado como indicador mais relevante no processo adsortivo de MC-LR.

\section{AGRADECIMENTOS}

Os autores agradecem ao $\mathrm{CNPq}$ pelas bolsas vinculadas à pesquisa, à Capes no contexto do programa Procad (Proc. 218/2007), à Finep idem do edital Saneamento e Habitação e à Fapemig ibidem do Programa Pesquisador Mineiro (Proc. 005313).

\section{REFERÊNCIAS}

ASSOCIAÇÃO BRASILEIRA DE NORMAS TÉCNICAS - ABNT. (1992) NBR 12216: Projeto de estações de tratamento de água para abastecimento público. Rio de Janeiro.

APHA; AWWA; WEF - American Public Health Association; American Water Works Association; Water Environment Federation. (2005) Standard methods for the examination of water and wastewater. 21 ed. Washington, D.C.: American Public Health Association.

BRADY, R.D. (1990) Activated carbon processes. In: Water treatment plant design AWWA \& ASCE. California: ASCE, p. 14.1-14.38

BRASIL. Ministério da Saúde. (2000) Normas e padrão de potabilidade da água destinada ao consumo humano. Portaria 1469. Brasília: Ministério da Saúde.

BRASIL. Ministério da Saúde. (2011) Normas e padrão de potabilidade da água destinada ao consumo humano. Portaria 2914. Brasília: Ministério da Saúde.

BAUTISTA-TOLEDO, I.; FERRO-GARCÍA, M.A; RIVERA-UTRILA, J.; MORENO-CASTILLA, C.; VEGAS FERNÁNDES, F.J. (2005) Bisphenol a removal from water by activated carbon, Effects of carbon characteristics and solution chemistry, Environmental Science Technology. v. 39, n.16, p. 6245-50.

CHOW, C.W.K.; DRIKAS, M.; HOUSE, M.; BURCH, M.D.; VELZEBOER, M.A. (1999) The impact of conventional water treatment processes on cells of the Cyanobacterium Microcystis aeruginosa. Water Research, v. 33, n. 15, p. 3253-3262.

DI BERNARDO, L. \& DANTAS, A.D. (2007) Métodos e técnicas de tratamento de água. São Paulo: Rima. p.784.

DRIKAS, M.; DIXON, M.; MORRAM, J. (2009) Removal of MIB and geosmin using granular activated carbon with and without MIEX pretreatment. Water Research, v. 43, n. 20, p. 5151-5159.
HO, L.; LAMBLING, P.; BUSTAMANTE, H.; DUKER, P.; NEWCOMBE, G. (2011) Application of powdered activated carbon for the adsorption of cylindrospermopsin and microcystin toxins from drinking water supplies. Water Research, v. 45, n. 9. p. 2954-2964.

HUANG, W.J.; CHENG, B.L.; CHENG, Y.L. (2007) Adsorption of microcystin-LR by three types of activated carbon. Journal of Hazardous Materials, v. 141, n. 1, p. 115-122.

IBGE. Instituto de Geografia Estatística. (2008) Disponível em: <http//:www.ibge.gov.br>. Acesso em: 27 ago. 2012.

JUANG, R.; KAO, H.; CHEN, W. (2006) Column removal of Ni (II) from synthetic electroplating waste water using a strongacid resin. Separation and Purification Technology, v. 49, n. 1, p. 36-42.

KURODA, E.K.; ALBUQUERQUE JÚNIOR, E.C:; DI BERNARDO, L.; TROFINO, J.C. (2005) Caracterização e escolha do tipo de carvão ativado a ser empregado no tratamento de água contendo microcistins. In: XXIII Congresso Brasileiro de Engenharia Sanitária e Ambiental. Campo Grande. Anais Eletrônicos, Campo Grande.

MALKOC, E \& NUHOGLU, Y. (2006) Removal of Ni(II) ions from aqueous solutions using waste of tea factory: Adsorption on a fixedbed column. Journal of Hazardous Materials, v. 135, n. 13, p. 328-336.

NEWCOMBE, G. (2006) Removal of natural organic material and algal metabolites using activated carbon. In: NEWCOMBE, G.; DIXON D. (Ed.) Interface science in drinking water treatment - Theory and applications. London: Elsevier, p. 133-177.

PENDLETON, P.; SCHUMANN, R.; WONG, S.H. (2001) Microcystin adsorption by activated carbon. Journal of Colloid and Interface Science, v. 240, n. 1, p. 1-8.

SATHISHKUMAR, M.; PAVAGADHI, $\quad$ S: $\quad$ VIJAYARAGHAVAN, K: BALASUBRAMANIAN, R: ONG, S.L. (2O10) Experimental studies on removal of microcystinLR by peat. Journal of Hazardous Materials, v. 184, n. 1-3, p. 417-424. 
SATHISHKUMAR, M.; PAVAGADHI, S.; VIJAYARAGHAVAN, K.; BALASUBRAMANIAN, R.; ONG, S.L. (2011) Concomitant uptake of microcystin-LR and RR by peat under various environmental conditions. Chemical Engineering Journal, v. 172, n. 2-3, p. 754-762.

SIVONEN, K. \& JONES, G. (1999) Cyanobacterial toxins. In: CHORUS, I.; BARTRAM, J. Toxic cyanobacteria in water. London: E \& FN Spon, p. 41-112.

TEIXEIRA, T.P.F; AQUINO, S.F; PEREIRA, S.I; DIAS, A. (2012) Use of calcined layered double hydroxides for decolorization of azo dyes solutions: equilibrium, kinetics and recycling studies. Environmental Engineering Science, v. 29, n. 7. p. 685-692.

VALDÉS, H.; SÁNCHEZ-POLO, M.; RIVERA-UTRILLA, J.; ZAROR, C.A. (2002) Effect of ozone treatment on surface properties of activated carbon. Langm., v. 18, n. 6, p. 2111-2116.
VASCONCELOS, J.F; BARBOSA, J.E.L.; DINIZ, C.R.; CEBALLOS, B.S.O. (2O11) Cianobactérias em reservatórios do Estado da Paraíba: ocorrência, toxicidade e fatores reguladores. Boletim da Sociedade Brasileira de Limnologia, v. 39. n. 2, p. 1-20.

VERONESI-VIANA, M.; .GIANI, A.; MELO, C.S.; GOMES, L.L.; LIBÂNIO, M. (2009) Avaliação da remoção de saxitoxinas por meio de técnicas de tratamento das águas de abastecimento. Revista de Engenharia Sanitária e Ambiental, v. 14, n. 2, p. 193-204.

WANG, W.; HO, L.; LEWIS, D.M.; BROOKES, J.D.; NEWCOMBE, G. (2007) Discriminating and assessing adsorption and biodegradation removal mechanisms during granular activated carbon filtration of microcystin toxins. Water Research, v. 41, n. 18, p. 4262-4270.

WORLD HEALTH ORGANIZATION - WHO. (1998) Guidelines for drinking water quality. Geneva: WHO. 